Article

\title{
Treatment of Oil-Contaminated Water by Modified Polysilicate Aluminum Ferric Sulfate
}

\author{
Zhaoyang You ${ }^{1}$, Li Zhang ${ }^{1}$, Shujuan Zhang ${ }^{1}$ (D), Yongjun Sun ${ }^{1, *}$ and Kinjal J. Shah ${ }^{2}$ (D) \\ 1 College of Urban Construction, Nanjing Tech University, Nanjing 211800, China; \\ youzhaoyang@163.com (Z.Y.); njzl@njtech.edu.cn (L.Z.); zhangshujuan525@sina.com (S.Z.) \\ 2 Graduate Institute of Environmental Engineering, National Taiwan University, 71 Chou-Shan Road, \\ Taipei City 10673, Taiwan; kinjalshah8@gmail.com \\ * Correspondence: sunyongjun@njtech.edu.cn; Tel.: +86-25-5813-9655
}

Received: 23 June 2018; Accepted: 18 July 2018; Published: 20 July 2018

\begin{abstract}
In this experiment, a variety of inorganic materials were simply compounded with Polysilicate Aluminum Ferric Sulfate (PSAFS) to treat emulsified oil-contaminated water. Manganese sulfate $\left(\mathrm{MnSO}_{4}\right)$, magnesium sulfate $\left(\mathrm{MgSO}_{4}\right)$, and zinc sulfate $\left(\mathrm{ZnSO}_{4}\right)$ were selected as the materials to modify PSAFS in order to obtain a coagulant with good flocculation performance. During the preparation of modified PSAFS, metal manganese, magnesium, and zinc were introduced for modification, and four factors were used to optimize the best proportion of modifiers and PSAFS. The results showed that the order of demulsification and oil-removal ability is as follows: Mn-PSAFS (Mn-modified PSAFS) > Zn-PSAFS (Zn-modified PSAFS) > Mg-PSAFS (Mg-modified PSAFS) > PSAFS . Modified PSAFS was characterized by infrared spectroscopy (IR) and a Scanning Electron Microscope (SEM). In the range of $604 \mathrm{~cm}^{-1}$ to $1200 \mathrm{~cm}^{-1}$, due to the complexation reaction between metal ions and polysilicic acid, the absorption peaks of the modified PSAFS and PSAFS were significantly different. SEM results revealed that the particles of the spatial network structure were fibrous and arranged more closely $(0.5 \mathrm{~mm} \times 50.0 \mathrm{~mm})$ than others. This study provided that the modified PSAFS had good potential application in treating emulsified oily wastewater in the future.
\end{abstract}

Keywords: oily wastewater; modified PSAFS; coagulant; coagulation; characterization

\section{Introduction}

Aquatic pollution is a worldwide problem mostly caused by anthropic activities and more efforts are needed to make water treatment a sustainable process. Several effective technologies and materials have been developed in recent years, such as salt elimination techniques for water reuse of industry plants [1], new continuous wastewater treatment process designs [2], the use of microbial fuel cells [3], and environmentally friendly materials for oily water separation [4]. As petroleum is still the main fossil fuel used as a source of energy, oil spillage remains inevitable.

Ship-sourced oil pollution was often caused by ship accidents or excessive emissions resulting from the misconduct of the operators [5,6], and the amount of such operational pollution has recently increased [7]. According to oil droplet size, the oil droplets in the wastewater are divided into four categories: oil slick, dispersed oil, emulsified oil, and dissolved oil [8]. Among them, emulsified oil is a colloidal dispersion of two immiscible liquid phases with thermodynamic instability and kinetic stability of the adsorption layer. It has three types: oil-in-water, water-in-oil, and water-in-oil-in-water [9]. Current treatment technology, like oily water separation devices, can not effectively treat the wastewater from ships that contained a large amount of emulsified oil; the illegal discharge of ship wastewater into the environment does great harm to the marine ecological environment. In addition, the Marine Environment Protection Committee (MEPC) and European 
Maritime Safety Agency (EMSA) stipulated that the oil content in the discharged water is not permitted to exceed $15 \mathrm{ppm}$ [10]. Still, high levels of emulsification exist due to the abundance of surfactants and complex components, such as iron-made inorganic ion in the wastewater from ships, and it is difficult to meet the standards of MEPC and EMSA. A large amount of emulsified oil contained in ship wastewater is discharged due to oil leakage from the ships' engines [11] and the extensive use of detergent [12]. Emulsified oil particles in wastewater have a small particle size and large viscosity with a negative charge [13]. If they are not treated adequately before being discharged into natural water bodies, they block gas exchange, affect photosynthesis, destroy ecological balance, contaminate the soil, and eventually do great harm to lives on this planet. Given the difficulties during treating processes and the potential threat to the environment, a practical and economical method should be chosen to solve the oily wastewater problem. Our research has great value in protecting marine ecology through developing high efficiency oil-removal products for oily wastewater treatment.

Gravity separation and coarse granulation methods can only remove floating and dispersed oil, both of which exhibited weak performance in treating emulsified oil in wastewater, as they almost had no demulsification capacity [14]. Membrane-separation technology has made significant progress in recent years; Zhuli et al. [15] manufactured a relatively low-cost multilayered mullite-titania composite ceramic hollow fiber microfiltration membrane that can remove fine oil droplets from $(O / W)$ emulsions. However, membrane separation had several issues, including clogging and high cost that limits its large-scale application [16]. Regarding the bioremediation method, ex situ biodegradation requires long residence time and a large area of facilities for treating oily wastewater [17] and in situ biodegradation has many unstable factors, such as competition between the introduced specific bacteria strained with indigenous species and the lack of nitrogen and phosphorus sources to support microorganisms [18]. As a new emerging treatment method, ultrasonic technology has not been widely used, as it cannot treat high-concentration emulsified water with a costly treatment process.

Coagulation is a physicochemical process that contains two methods: coagulation and flocculation [19]. In the first step, coagulants can reduce the repulsive force of the electric double-layer colloids; then, colloids are destabilized and form into tiny aggregates. Then, microparticles begin to develop and gradually aggregate into larger particles, or flocs [20]. The coagulation process can reduce the colority and turbidity of water, remove a variety of macromolecules, organic matter, heavy metals, and radioactive substances, as well as bacteria, viruses, and nutrients that cause waterbody eutrophication. The coagulation process has the advantage of cost-effectiveness, and the process is simple and easy to control, so it is widely used in water and wastewater treatment. Currently, the coagulation process is indispensable in urban water supply treatment [21]; it is also commonly used in wastewater treatment in various industries, such as petrochemicals, steel, metallurgy, printing and dyeing, papermaking, food, and brewing [22]. The type and dosage of coagulant is the most important factor, among others, such as colloidal impurities, $\mathrm{pH}$ value, water temperature, the concentration of suspended solids, and hydraulic condition [21]. At present, coagulants used in water remediation developed from low molecular weight to polymeric coagulants, from inorganic to organic, from single-component to composite types; the removal mechanism of oily wastewater by each coagulant is not the same. The effect of polymeric coagulants to treat oily wastewater with complex components is much better than that of inorganic salt coagulants, and the required dosage is small [23]. Zawawi Daud et al. compared aluminum sulfate, polyaluminum chloride, ferric chloride, ferric sulfate, and alum $(450,300,350,450,500 \mathrm{mg} / \mathrm{L})$ under the condition of $2680 \mathrm{mg} / \mathrm{L}$ oily wastewater. The result showed that, when the dosage of polyaluminum chloride (PAC) was $300 \mathrm{mg} / \mathrm{L}$, the removal rate of oil material in the waste water could reach $97 \%$ [24].

Polysilicate aluminum ferric sulfate (PSAFS) is a new type of high-efficiency inorganic polymer coagulant. It has a good demulsification effect on emulsified oily wastewater [25]. To further reduce the dosage of flocculation, we tried to improve the preparation method of PSAFS and modify it. In this experiment, we investigated the impacts of $\mathrm{nAl}: \mathrm{nFe}, \mathrm{n}(\mathrm{Fe}+\mathrm{Al}): \mathrm{nSi}$, sodium silicate concentration and basicity on the PSAFS coagulation effect. We also combined manganese ion, zinc ion, magnesium ion, 
sodium chloride, and bentonite with PSAFS and then chose some of them to introduce into polysilicic acid as a modifier. We also investigated the effect of molar ratio of modified ions to silicon ions and the impact of their internal structure on the coagulation process.

\section{Materials and Methods}

\subsection{Materials}

All the agents used in the research, including aluminum sulfate, sodium chloride, magnesium sulfate, anhydrous sodium sulfate, sodium hydroxide, zinc sulfate, manganese sulfate, sodium silicate, sodium chlorate, ferrous sulfate, sulfuric acid, petroleum ether, sodium dodecylbenzenesulfonate, and triiron tetroxide were analytically pure, and sourced from Nanjing Shengsound Instrument Chemical Glass Co., Ltd. (Nanjing, China). Polyaluminum ferric chloride (PAFC), polymeric aluminum ferric silicate (PSAF), and polyacrylamide (PAM) were industrial grade and also purchased from Nanjing Shengsound Instrument Chemical Glass Co., Ltd. The solution was prepared with deionized (DI) water throughout the experiment.

\subsection{Synthetic Ship Oil-Contaminated Water}

Synthetic ship oily wastewater was prepared according to the International Maritime Organization (IMO) document MEPC.107(49). The amount of sodium dodecyl benzene sulphonate (SDBS) were weighed and dissolved in DI water to make a mixed solution. Then, 1.2 times the amount of DI water was injected into the container, and the centrifugal pump was turned on and adjusted to a rotation speed of no less than $3000 \mathrm{rpm}$. The flow rate of the liquid was adjusted so that it could be recycled at least once every minute, and we then added 1.2 times the amount of oil and $\mathrm{Fe}_{3} \mathrm{O}_{4}$ solids. In order to stabilize the emulsified state of the liquid in the container, the centrifugal pump needed at least $1 \mathrm{~h}$ continuous operation. Finally, the rotation of the speed of the centrifugal pump was adjusted to $300 \mathrm{r} / \mathrm{min}$ for the rest of the test. The composition and the characteristics of the synthetic emulsified oily wastewater are shown in Table 1.

Table 1. The composition and the characteristics of emulsified oil wastewater.

\begin{tabular}{cccccc}
\hline $\begin{array}{c}\text { Composition } \\
(\mathrm{g} / 1000 \mathrm{~g})\end{array}$ & $\begin{array}{c}\text { Freshwater } \\
947.8\end{array}$ & $\begin{array}{c}\text { Fuel oil A } \\
25.0\end{array}$ & $\begin{array}{c}\text { Fuel oil B } \\
25.0\end{array}$ & $\begin{array}{c}\text { SDBS } \\
0.5\end{array}$ & $\begin{array}{c}\mathrm{Fe}_{3} \mathrm{O}_{4} \\
1.7\end{array}$ \\
\hline \multirow{3}{*}{ Characteristics } & $\begin{array}{c}\text { Oil concentration } \\
\left(\mathrm{mg} \cdot \mathrm{L}^{-1}\right)\end{array}$ & $\begin{array}{c}\text { Turbidity } \\
(\mathrm{NTU})\end{array}$ & $\mathrm{pH}$ & $\begin{array}{c}\text { Droplets diameter } \\
(\mu \mathrm{m})\end{array}$ & $\begin{array}{c}\mathrm{COD} \\
\left(\mathrm{mg} \cdot \mathrm{L}^{-1}\right)\end{array}$ \\
& $3000 \sim 5000$ & $7000 \sim 10,000$ & $6.5 \sim 6.8$ & $10 \sim 15$ & $7800 \sim 17,000$ \\
\hline
\end{tabular}

Note: Fuel oil A is RGM35 (density $\geq 980 \mathrm{~kg} / \mathrm{m}^{3}$ ), distillate oil fuel B is DMA (density $\geq 830 \mathrm{~kg} / \mathrm{m}^{3}$ ), and particle size distribution of $\mathrm{Fe}_{3} \mathrm{O}_{4}$ is $\mathrm{D}_{90}=10 \mu \mathrm{m}$.

\subsection{Preparation of PSAFS and Modified PSAFS}

\subsubsection{Choice of Modifier}

The coagulation experiment was conducted by compounding the modifiers with aluminum polysilicate iron, $300 \mathrm{mg}$ PSAFS, and five different kinds of alternative modifiers: $\mathrm{NaCl}, \mathrm{MnSO}_{4}, \mathrm{MgSO}_{4}$, $\mathrm{ZnSO}_{4}$, and bentonite, which were weighed and added to $1000 \mathrm{~mL}$ of emulsified oily wastewater separately. After stirring for $5 \mathrm{~min}$ (350 rpm), the precipitate was settled down.

\subsubsection{PSAFS Preparation and Modification Process}

The PSAFS preparation process is shown in Figure 1. We dissolved sodium silicate in water glass solutions of different molar concentrations (calculated as $\mathrm{SiO}_{2}$ ), then gradually added them to a $20 \%$ dilute sulfuric acid solution and stirred at a certain temperature. We would stop this process and adjust the $\mathrm{pH}$ until the solution turned blue, when the silicic acid had been polymerized into activated 
silicic acid. Afterwards, we dissolved aluminum sulfate, ferrous sulfate, etc. in order to dilute sulfuric acid until it was completely dissolved. We added the solution to the activated silicic acid and stirred at a certain temperature to initiate the polymerization process. Finally, we added sodium hydroxide to the solution for adjusting the degree of basicity, stirred, and let it stand for $24 \mathrm{~h}$ before drying it in an oven to obtain the PSAFS product. In the condition of $0.5 \mathrm{~mol} / \mathrm{L} \mathrm{Si}, 50 \%$ basicity (B), $\mathrm{n}(\mathrm{Al}+\mathrm{Fe}): \mathrm{nSi}$ was 10:1, and nAl:nFe is 1:1, manganese salt, magnesium salt, and zinc salt, respectively, were used to modify PSAFS. The coagulation tests were conducted to determine the optimal nMn:nSi, $\mathrm{nMg}: \mathrm{nSi}$, and nZn:nSi values.

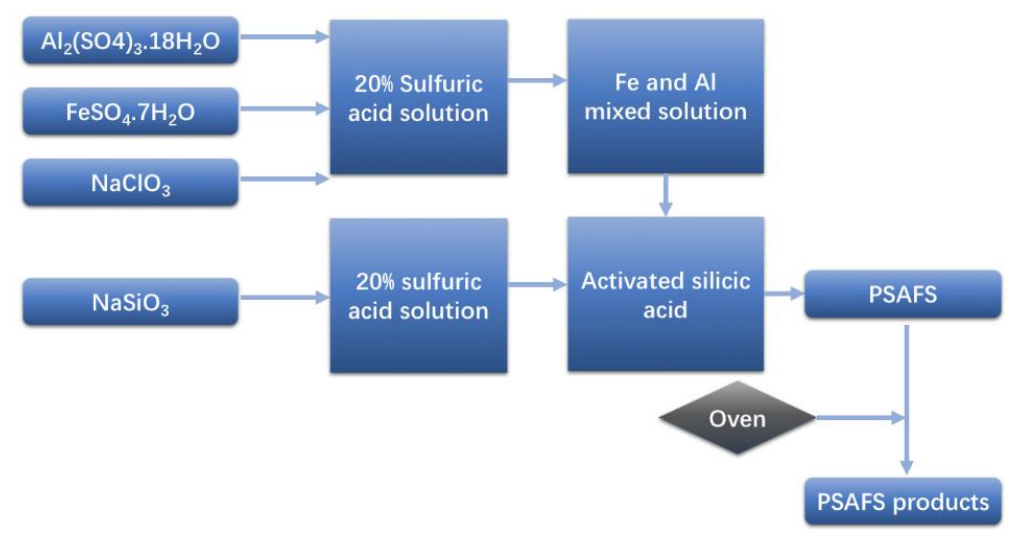

Figure 1. Preparation of polysilicate aluminum ferric sulfate (PSAFS).

\subsection{Characterization}

The prepared liquids Mn-PSAFS, Mg-PSAFS, and Zn-PSAFS were cured in an oven at $60{ }^{\circ} \mathrm{C}$ for $48 \mathrm{~h}$, then ground to obtain a yellow powder, scanned with the Scanning Electron Microscope (SEM) and performed IR spectroscopy analysis using a KBr pellet.

\subsection{Coagulation and Coagulation-Flotation Tests}

We took $200 \mathrm{mg}, 300 \mathrm{mg}, 400 \mathrm{mg}, 500 \mathrm{mg}, 600 \mathrm{mg}$, $700 \mathrm{mg}$ of Mn-PSAFS, Mg-PSAFS, Zn-PSAFS and commercial PSAFS, PAC, PAFC coagulant, respectively, to conduct a coagulation test on $1000 \mathrm{~mL}$ of emulsified oil wastewater with 4000 ppm oil. Ultraviolet spectrophotometry measured the oil concentration in water. The water samples to be tested were placed in a $1000 \mathrm{~mL}$ separatory funnel, and petroleum ether could extract oil component, which we then collected in a volumetric flask. The extraction process was repeated twice, and the final volume was diluted with petroleum ether in a $50 \mathrm{~mL}$ volumetric flask until it reached the mark. The optical density (OD) was measured with an ultraviolet spectrophotometer at a wavelength of $256 \mathrm{~nm}$. We calculated the final oil concentration through the standard curve we made. NTU was the unit of turbidity, and turbidity was determined by a turbidimeter (2100Q, HACH, Loveland, CO, USA). The water samples were taken into the detection bottle, and then put into the turbidimeter for detection. Basicity was the mass ratio of $(\mathrm{OH}) /[\mathrm{n}(\mathrm{Fe})]$, which was determined according to the Chinese national standard (GB 14591-2016)

\section{Results and Discussion}

\subsection{Selection of Modifiers}

As can be seen in Figure 2, after using these alternative-modifier composite PSAFS to treat 5000 ppm emulsified oily wastewater, magnesium sulfate, zinc sulfate, and manganese sulfate could make the effluent oil concentration below $15 \mathrm{mg} \cdot \mathrm{L}^{-1}$, so the deoiling effect was significant. When the dosage of magnesium sulfate and zinc sulfate was $200 \mathrm{mg} \cdot \mathrm{L}^{-1}$, the oil concentration was reduced to $12.75 \mathrm{mg} \cdot \mathrm{L}^{-1}$ and $12.17 \mathrm{mg} \cdot \mathrm{L}^{-1}$, and when the dosage of manganese sulfate was $400 \mathrm{mg} \cdot \mathrm{L}^{-1}$, the oil 
content in the effluent reaches $10.51 \mathrm{mg} \cdot \mathrm{L}^{-1}$; this amount was more significant than magnesium sulfate and zinc sulfate. The addition of sodium chloride and bentonite had no noticeable demulsification effect on the oily wastewater. According to the results, we chose magnesium sulfate, zinc sulfate, and manganese sulfate as the modifiers.

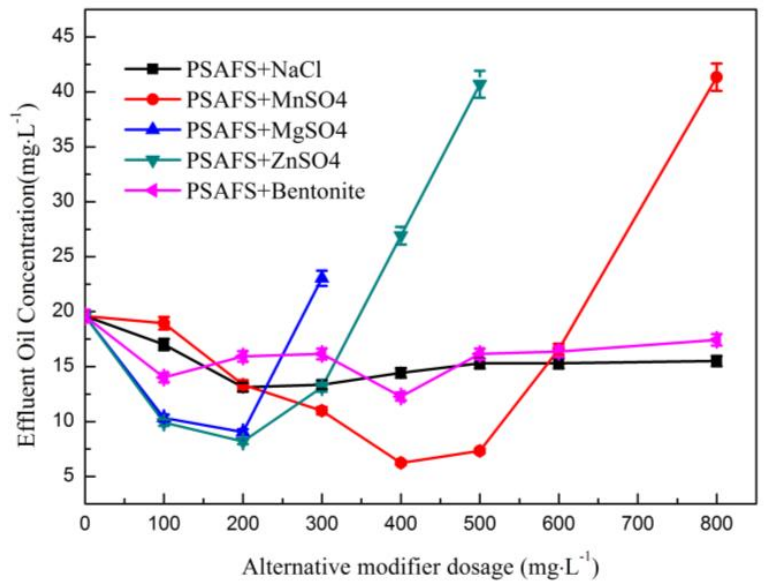

Figure 2. Influence of addition of alternative modifiers on deoiling effect of PSAFS.

\subsection{Factors Affecting Demulsification during Preparation of PSAFS}

\subsubsection{Sodium Silicate Concentration}

As shown in Figure 3, when the concentration of sodium silicate was less than $0.5 \mathrm{~mol} \cdot \mathrm{L}^{-1}$, PSAFS had better a demulsification effect on emulsified oil wastewater as the concentration of Si ions increased. However, the effect gradually weakened as the concentration of Si ions continued to increase. It was found that when the concentration of Si ions was too low, PSAFS would gel in a short time, so that the curing process was affected, and the effect of demulsification was much lower than that of PSAFS with high Si concentration. It may be because when the concentration of sodium silicate was low, the requirement of low-concentration sodium silicate solution grew to prepare the same quality of PSAFS, which diluted the concentration of PSAFS solution. In the same volume of PSAFS, the concentration of Fe and Al ions, which play critical roles in demulsification, was much lower than that of PSAFS prepared with the higher concentration of sodium silicate solution. So we chose to use $0.5 \mathrm{~mol} \cdot \mathrm{L}^{-1}$ sodium silicate solution for developing the activated silicic acid.

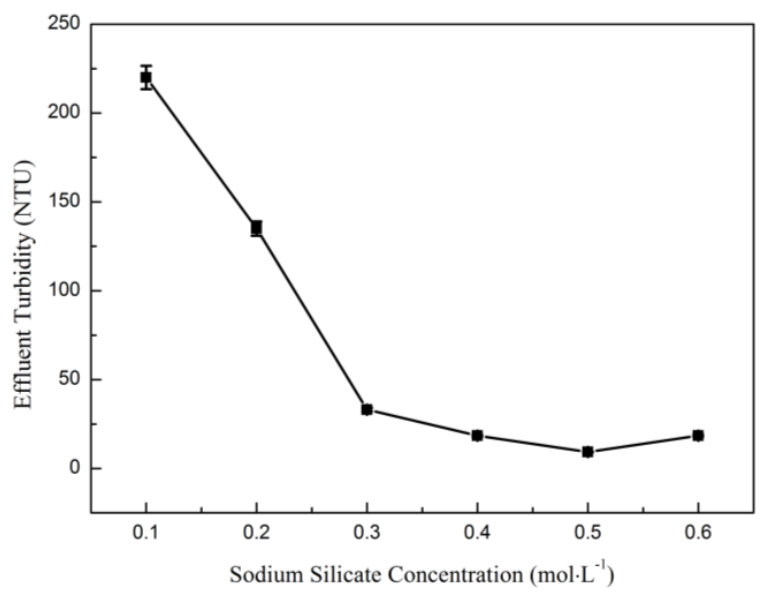

Figure 3. Influence of sodium silicate concentration on oil-removal ability of PSAFS. 


\subsubsection{Degree of Basicity}

According to the test, the degree of basicity had a significant influence on the PSAFS oil-removal capacity; the results are shown in Figure 4. In the beginning, with the increase of basicity, the turbidity-removal ability of PSAFS on oily water improved, and the effluent turbidity gradually decreased. However, as the B value increased to more than $30 \%$, its effect decreased.

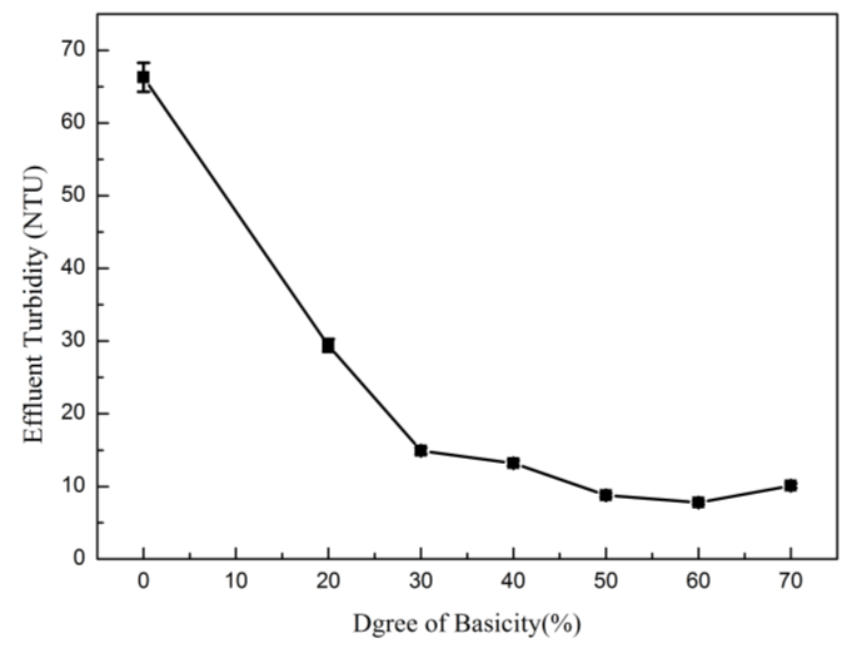

Figure 4. Effect of PSAFS basicity on turbidity removal.

As the degree of basicity increased, the polymerization of PSAFS would increase accordingly. However, when the degree of basicity was too high, the coagulant would generate a significant amount of high polymer after hydrolysis, which would reduce the formation of multinuclear hydroxy complexes of aluminum and iron, thereby significantly decreasing the stability of the coagulant, the phenomena of wall-hanging and poor flocculation would occur during the treatment process. When the alkalinity was too low, the molecular chain of PSAFS was short, and the degree of polymerization was low, so its adsorption and bridging effect were reduced. We analyzed the turbidity-removal effect when the basicity value ranged from $30 \%$ to $70 \%$; from an economical point of view, the degree of basicity of the coagulant we chose in this test was $50 \%$.

\subsection{3. $\mathrm{n}(\mathrm{Al}+\mathrm{Fe}): \mathrm{nSi}$ and $\mathrm{nAl}: \mathrm{nFe}$}

From Table 2, it can be seen that the value of $\mathrm{n}(\mathrm{Al}+\mathrm{Fe})$ :nSi significantly influenced the demulsification and turbidity removal of PSAFS-treated emulsified oil wastewater. Under certain $\mathrm{nAl}: \mathrm{nFe}$ values; with the decrease of $\mathrm{n}(\mathrm{Al}+\mathrm{Fe}): \mathrm{nSi}$, the demulsification and turbidity-removal effect of PSAFS on emulsified oil wastewater gradually decreased, and the effluent turbidity increased. When $\mathrm{n}(\mathrm{Al}+\mathrm{Fe}): \mathrm{nSi} \geq 10$, the impact of PSAFS on emulsified oil wastewater did not change significantly as the ratio increased; this was because a large amount of silicon in the coagulant reduced its electrical neutralization capacity. If the concentration of aluminum and iron in the coagulant was too high, the activated silicic acid could not completely coordinate it. After treatment, the effluent would contain a significant amount of aluminum and iron ions, which can cause secondary pollution.

Under certain $\mathrm{n}(\mathrm{Al}+\mathrm{Fe}): \mathrm{nSi}$ values, the flocs formed by PSAFS were large and light when the value of nFe:nAl was small, and the flocculation performance decreased. However, when the content of aluminum ions was high, the electrostatic repulsion between ions was small, and the silicon-oxygen chain tended to form a wrap-like mass. Only by adding an appropriate amount of aluminum salt could the electrostatic repulsive force fully extend the silicon-oxygen chain into a long chain shape. When the nFe:nAl value was high, the flocs were dense, and their sedimentation performance was 
good, but excessive iron content would increase the colority of the effluent. After a comprehensive consideration, $\mathrm{nAl}: \mathrm{nFe}=1: 1$ and $\mathrm{n}(\mathrm{Al}+\mathrm{Fe}): \mathrm{nSi}=10: 1$ were chosen as the optimal value.

The NTU values of untreated shipwater for ease of comparison were 7000 10,000 NTU.

Table 2. $\mathrm{n}(\mathrm{Al}+\mathrm{Fe}): \mathrm{nSi}$ and $\mathrm{nAl}: \mathrm{nFe}$ orthogonal test table.

\begin{tabular}{cccccccc}
\hline & \multicolumn{7}{c}{ nFe:nAl } \\
\cline { 3 - 8 } & & $\mathbf{4 : 1}$ & $\mathbf{2 : 1}$ & $\mathbf{1 : 1}$ & $\mathbf{1 : 2}$ & $\mathbf{1 : 4}$ & $\mathbf{1 : 6}$ \\
\hline & Untreated & \multicolumn{7}{c}{7000} \\
\hline \multirow{3}{*}{ n(Fe+Al):nSi } & $20: 1$ & 74.0 & 27.8 & 12.7 & 14.3 & 33.3 & 46.2 \\
& $15: 1$ & 85.0 & 33.5 & 11.8 & 13.5 & 14.2 & 27.9 \\
& $10: 1$ & 85.7 & 26.8 & 9.69 & 11.3 & 12.16 & 21.4 \\
& $5: 1$ & 108.1 & 89.8 & 76.5 & 55.8 & 55.6 & 87.6 \\
& $1: 1$ & 100.8 & 57.2 & 118 & 125.6 & 125.3 & 143.6 \\
\hline
\end{tabular}

Note: The value in Table 2 is the effluent turbidity in NTU. The NTU values of the untreated shipwater for ease of comparison were $7000 \sim 10,000$ NTU.

\subsection{Modification Effects of PSAFS}

\subsubsection{Manganese Salt}

Figure 5 shows that when nMn:nSi was 6:1 and 4:1, Mn-PSAFS had a good demulsification and turbidity-removal effect on emulsified oil wastewater. Especially at 6:1, the effluent turbidity could be reduced to $6.96 \mathrm{NTU}$. As the nMn:nSi ratio decreased, the demulsification and turbidity-removal effect of Mn-PSAFS gradually decreased. This was because when a small amount of manganese salt was introduced, the divalent manganese ion was easily oxidized and could not form effective coordination with the activated silicic acid, so an effective flocculating component could not be created. That was why, when the manganese ion content in the coagulant was low, the flocculation effect was weak. When the ratio of nMn:nSi increased, Mn-PSAFS gradually increased demulsification and turbidity-removal capacity; this was because the surface of manganese salt had abundant surface hydroxyl groups. Its introduction made Mn-PSAFS able to form a more compact fibrous structure. As the effective coordination of the manganese ions and the activated silicic acid caused the coagulation agent to accumulate more charge, the entrapment and sweeping of the coagulant, the neutralization ability, and the stability of the coagulant were enhanced. Also, although the introduction of manganese salt improves the settling performance of flocs, excessive manganese ions would affect the coordination of aluminum, iron, and activated silicic acid, reduce the content of aluminum and iron ions in coagulant, and weaken the coagulant demulsification and oil-removal ability. Based on the experimental results, we chose nMn:nSi to be 6:1.

\subsubsection{Magnesium Salt}

Figure 6 shows that when nMg:nSi was 1:1, Mg-PSAFS had the best effect of demulsification and turbidity-removal on emulsified oil wastewater, and the effluent turbidity could be reduced to $8.33 \mathrm{NTU}$. With the decrease of the $\mathrm{nMg}: \mathrm{nSi}$ value, the demulsification and turbidity-removal effects of Mg-PSAFS on emulsified oil wastewater were reduced because the coagulant was anionic when the magnesium salt dosage was low, and it was hard to neutralize the negatively-charged oil droplets. With the increase of $\mathrm{nMg}: \mathrm{nSi}$ value, the neutralization capacity of the coagulant gradually increased, but excessive magnesium ions would attach to the floccule particle to make it positively charged, thereby weakening the adsorption and bridging ability of the coagulant. As the dosage continued to increase, the treatment effect was reduced; this was because when the coagulant overdosed, the flocs would repel each other due to having the same charge and slowing down settling speed. The addition of magnesium salt can let the coagulant dissolve more quickly and produce large, dense, and easily-settled flocs. The introduction of magnesium salt in PSAFS could not only enhance the decolorization effect 
of the coagulant but also strengthen its ability to neutralize and adsorb bridges. The addition of magnesium salt also shortened the curing time of the coagulant, and a small amount of magnesium hydroxide was generated in the reaction system. It had strong activity, ability, and buffer capacity, and could assist in adsorbing oil particles remaining in the water.

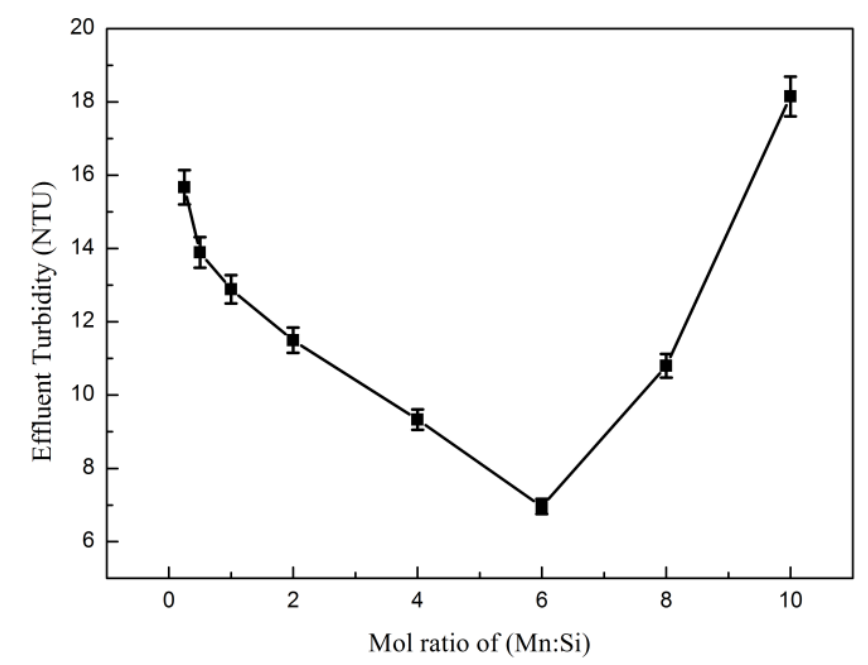

Figure 5. Effect of nMn:nSi on Mn-PSAFS removal of turbidity.

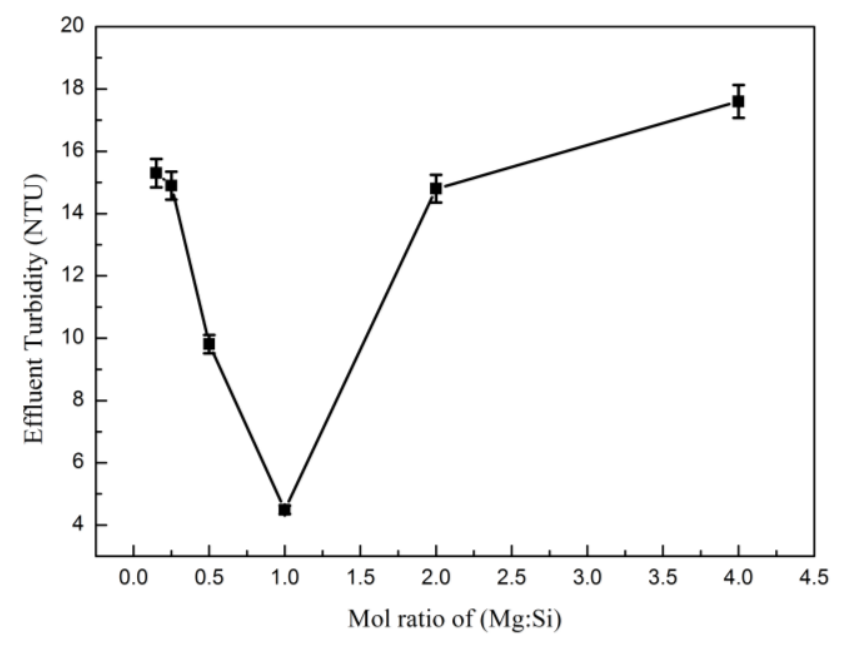

Figure 6. Effect of nMg:nSi on the Mg-PSAFS removal of turbidity.

\subsubsection{Zinc Salt}

As Figure 7 shows, when the value of nZn:nSi was between 4 and 8, Zn-PSAFS had a good effect on demulsification and turbidity removal of emulsified oil wastewater. With the increase of dosage of coagulant, its treatment effect gradually increased, and the effluent turbidity decreased. When the dosage was $1.2 \mathrm{mg} \cdot \mathrm{L}^{-1}$, the treatment effect was the best. At that time, the concentration of Zn-PSAFS polymer in the reaction system was higher, and the collision probability between the colloidal particles was substantially increased, which was favorable for the adsorption and bridging between the colloidal particles. When the value of nZn:nSi was small, the amount of flocs formed after Zn-PSAFS was dissolved was too small. When the value of $\mathrm{nZn}: \mathrm{nSi}$ was high, the activated silicic acid could not be fully utilized, which affected the polymerization degree of the coagulant. 


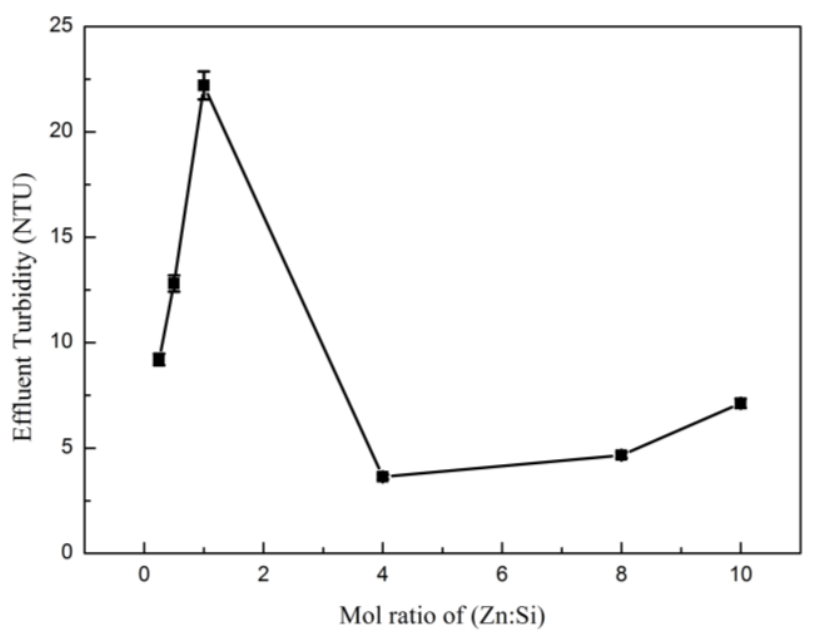

Figure 7. Effect of nZn:nSi on the Zn-PSAFS removal of turbidity.

The introduction of zinc salt made PSAF form a chain network and layered structure. As the value of $\mathrm{nZn} n \mathrm{nSi}$ increased, a coordination reaction occurred between the zinc ion hydrolyzed polymer and the hydroxyl group of the chain polysilicic acid molecule, resulting in the chain network and layer structure of Zn-PSAFS also gradually increased. However, if too much zinc salt were introduced, it would not only hinder the adsorption of colloidal particles by flocs but also cause gelation of Zn-PSAFS in a short time. The introduction of zinc ions in PSAFS led to the formation of dense flocs during a short period, and a large-scale microflocculation-trapping system started to appear, the sedimentation rate was fast, but the required dosage of coagulant was large. So as a result, we chose nZn:nSi to be 4 .

\subsection{Comparison of Modified Coagulants}

Figure 8 shows that the demulsification and oil-removal effects of $\mathrm{Mn}$-, $\mathrm{Mg}$-, and $\mathrm{Zn}$-modified PSAFS coagulants on emulsified oil wastewater were better than those of commercially available PSAFS, PAC, and PAFC. The effluent oil concentration after treatment could be reduced to less than $10 \mathrm{mg} \cdot \mathrm{L}^{-1}$.

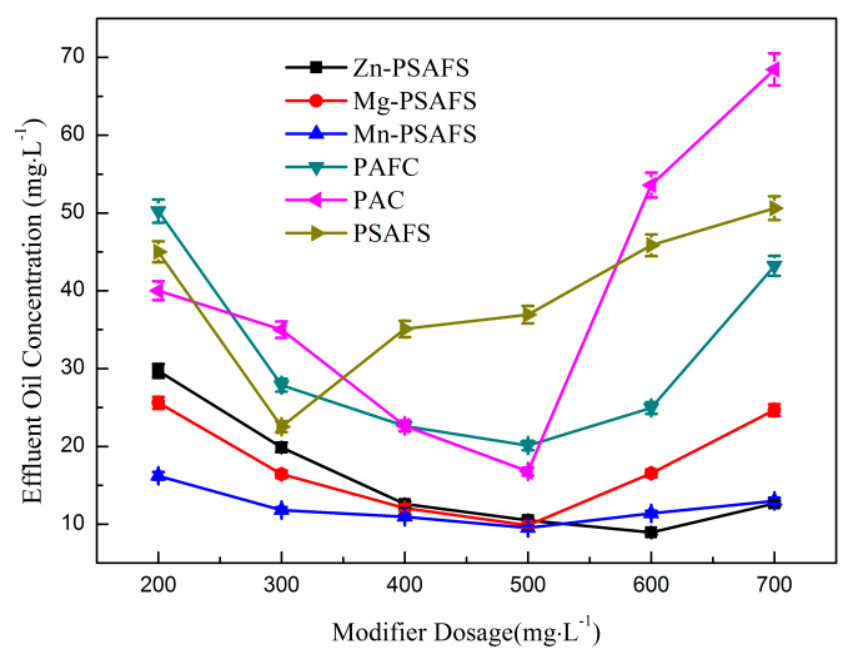

Figure 8. Oil-removal performance comparison.

Modified coagulants not only reduced the concentration of oil in the effluent but could also make the flocculation state. The modified coagulants produced large and dense flocs with good 
settling performance in the process of treatment, and the amount of dross (trash) was less than that of commercial coagulants. The flocs that formed from commercial coagulants were apparently smaller than modified coagulants. Among the modified coagulants, the flocs of Mg-PSAFS were smaller than those of Zn-PSAFS and Mn-PSAFS. After standing, the residual microflocs in the water layer were more than those of Zn-PSAFS and Mn-PSAFS. In addition, the settling performance of commercial coagulants was worse than that of modified coagulants, and the settling velocity was slow. As the magnesium, zinc, and manganese were introduced into the PSAFS as modified ions, the molecular weight of these coagulants was increased, so not only its settling velocity was improved, but also the water in the flocs could be rapidly extruded during the sedimentation process, so that the water content of dross and the amount of scum were reduced. Due to the introduction of new metal ions in the hydrolysis process, the hydroxyl structure of the primary coagulant was changed. Therefore, the flocs formed by the modified coagulant would be more compact during the process that coordinated with the activated silicic acid. The treatment effect of Mn-PSAFS on emulsified oily wastewater was more stable than that of Zn-PSAFS. Under the same deoiling effect, the dosage of Mn-PSAFS was less than Zn-PSAFS; under the same dosage, the oil-removal rate of emulsified oil wastewater by Mn-PSAFS was better than that of Mg-PSAFS. Based on experimental data and analysis results, we believe that manganese ion was the best modified metal ion for PSAFS.

\subsection{Characterization Results Analysis}

\subsubsection{IR Spectroscopy Analysis Results}

As can be seen from the Figure 9, the spectra of PSAFS, Mn-PSAFS, Mg-PSAFS, and Zn-PSAFS are the same, with high light transmittance absorption peaks near $3200 \mathrm{~cm}^{-1} \sim 3600 \mathrm{~cm}^{-1}, 3390 \mathrm{~cm}^{-1}$ and $3310 \mathrm{~cm}^{-1}$, respectively, which was the vibrational absorption peaks of $-\mathrm{OH}$ group. $\mathrm{Fe}, \mathrm{Al}$, metal $\mathrm{Mn} / \mathrm{Mg} / \mathrm{Zn}$ ions, and their hydrolyzed complex ions tend to complex with -OH groups. After infrared spectroscopic analysis, the metal ions manganese, zinc, and magnesium all underwent complex reactions with the activated silicic acid, rather than the pure compound of several compounds.

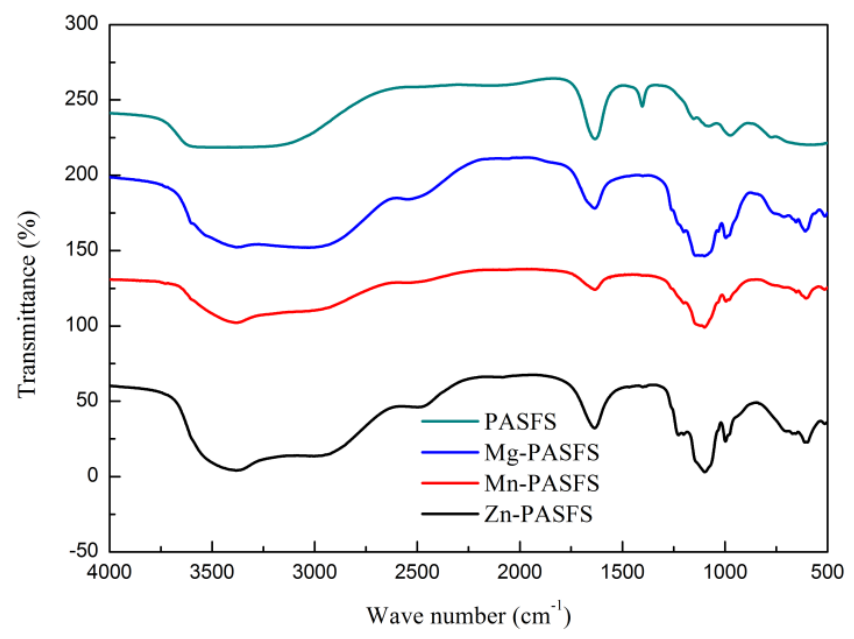

Figure 9. IR spectra of coagulants.

Taking Mn-PSAFS as an example, the absorption peak near $1620 \mathrm{~cm}^{-1}$ is generated by bending vibration of $\mathrm{H}-\mathrm{O}-\mathrm{H}$. Therefore, it was known that Mn-PSAFS was not a mixture of several substances but a hydroxy complex. The peak near $2490 \mathrm{~cm}^{-1}$ was mainly produced by $\mathrm{Mn}-\mathrm{O}, \mathrm{Fe}-\mathrm{O}$ and Al-O. The absorption peak near $1110 \mathrm{~cm}^{-1}$ was wider than PSAFS and the intensity increased, mostly because the $\mathrm{Mn}-\mathrm{OH}-\mathrm{Mn}, \mathrm{Al}-\mathrm{OH}-\mathrm{Al}$, and $\mathrm{Fe}-\mathrm{OH}-\mathrm{Fe}$ stretching vibrations generated higher wave numbers and the angles between them and the properties of adjacent elements affected their position in the infrared 
spectrum, which may have been due to the presence of manganese ions in the complexation reaction. The peak near $604 \mathrm{~cm}^{-1}$ was attributed to Si-O bending vibration, and the peak near $1200 \mathrm{~cm}^{-1} \mathrm{was}^{-}$ attributed to the vibration of Mn-O-Si, Fe-O-Si and Al-O-Si [21]. The reason why the absorption peaks of Mn-PSAFS, Zn-PSAFS and Mg-PSAFS from $604 \mathrm{~cm}^{-1}$ to $1200 \mathrm{~cm}^{-1}$ were distinctly different from those of PSAFS, especially around $1410 \mathrm{~cm}^{-1}$ where only PSAFS had a distinct peak, may have been due to the complex reaction of the modified metal ions with polysilicic acid near the change point [26].

The absorption peak of Mn-PSAFS near $1200 \mathrm{~cm}^{-1}$ was larger than that of Zn-PSAFS, Mg-PSAFS and PSAFS. It may be because the introduction of Mn ions in that vicinity made the vibrational intensities of Mn-O-Si, Fe-O-Si and Al-O-Si larger than those caused by $\mathrm{Mg}$ and $\mathrm{Zn}$ ions. This was an important feature of Mn-PSAFS that distinguished it from Zn-PSAFS and Mg-PSAFS. The high light transmittance meant that there were few impurities, and the metal ions could combine with nonionic bonds on the activated silicic acid. It may have been the key reason why the modified coagulant had a higher treatment effect on the emulsified oil wastewater than unmodified coagulants.

\subsubsection{SEM Results}

From the SEM image of these coagulants, as seen in Figure 10, PSAFS was a spatial network with more pores. Mn-PSAFS had a similar spatial network structure as PSAFS, but its constituent particles were fibrous structures that were arranged more closely $(0.5 \mathrm{~mm} \times 50.0 \mathrm{~mm})$ than PSAFS and had more internal porosity. Mg-PSAFS and Zn-PSAFS coagulants shared a similar structure of layers.

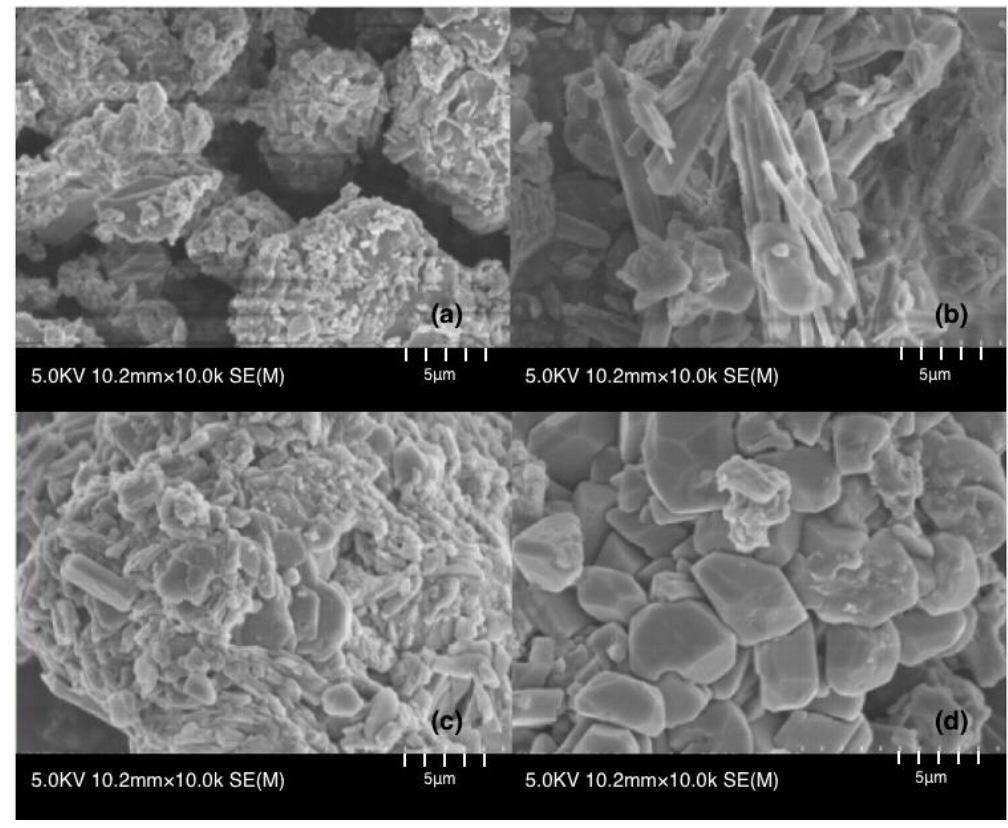

Figure 10. SEM Images: (a) PSAFS SEM image; (b) Mn-PSAFS; (c) Zn-PSAFS; (d) Mg-PSAFS.

The reason why PSAFS was a spatial network structure with many pores was that $\mathrm{Al}$ and Fe were ion hydrolyzated complexes with -OH of polysilicic acid [27]. Due to the tetrahedral arrangement of the silicic acid molecule, each silicon atom could undergo hydroxyl bridging with $\mathrm{Al}$ and Fe ions and finally form a network structure. When the flocculation reaction occurred, the network structure could better adsorb and bridge the oil particles in the emulsion and enhance the trapping and complete performance of the coagulant.

The tight fibrous structure of Mn-PSAFS could further enhance the adsorption and bridging than PSAFS. The introduction of metallic manganese enhanced the electrical neutralization of PSAFS, making it easy to demulsify the emulsified oily wastewater. From IR spectroscopy analysis, we saw that Mn-PSAFS could also be bridged with -OH to form Mn-O-Al and Mn-O-Fe bonds, and Mn and 
Si-OH complexation reaction produced Si-O-Mn bonds to make Mn-PSAFS have more branched chains; macromolecules with higher degree of polymerization were established at the same time, which improved the stability of the coagulant. Both the Mg-PSAFS and Zn-PSAFS coagulants had a layered structure. The regularly stacked laminated particles of Mg-PSAFS and Zn-PSAFS had a larger surface area than PSAFS, and higher porosity also enhanced their adsorption and bridging properties. Similar to the introduction of $\mathrm{Mn}$, the introduction of $\mathrm{Mg}$ and $\mathrm{Zn}$ could also span the polynuclear hydroxy complex with -OH to form the corresponding bond structure. Different from other coagulants, Zn-PSAFS also had a chain network structure, and spherical particles were formed on the flaky particles. The introduction of zinc helped the coagulant form more microfloc structures so that it could enhance PSAFS's catching ability [26].

In summary, after SEM observation and experimental data analysis, we believe that the fibrous spatial network of an Mn-PSAFS coagulant was more suitable for emulsified oil wastewater treatment. This may be because the fibrous particles were more conducive to the attachment and aggregation of the oil particles, thereby enhancing the oil-removal performance of the coagulant.

\section{Conclusions}

In this research, we chose the modifiers through preliminary experiments, and several coagulation tests were conducted to improve the PSAFS preparation and modification process. The comparison of oil-removal capacity was done between several coagulants, and, finally, the characterization of modified and unmodified PSAFS was used to learn more about these phenomena by observing their internal structure.

(1) When PSAFS was combined with magnesium sulfate, zinc sulfate, and manganese sulfate to treat emulsified wastewater with $5000 \mathrm{ppm}$ oil, the effluent oil concentration can be reduced to less than $15 \mathrm{ppm}$. Although the dosage of $\mathrm{MnSO}_{4}$ was larger than that of $\mathrm{MgSO}_{4}$ and $\mathrm{ZnSO}_{4}$, the efficiency of oil-removal was the highest. The effluent oil content can be reduced to $10.51 \mathrm{mg} \cdot \mathrm{L}^{-1}$. The PSAFS demulsification effect of emulsified oil wastewater with $\mathrm{NaCl}$ and bentonite was not obvious. (2) The main factors affecting the flocculation performance of PSAFS were sodium silicate concentration, basicity, $\mathrm{n}(\mathrm{Al}+\mathrm{Fe}): \mathrm{nSi}$, and $\mathrm{nAl}: \mathrm{nFe}$. Through experiments, we chose sodium silicate $0.5 \mathrm{~mol} / \mathrm{L}$, basicity $50 \%$, nAl:nFe 1:1, basicity 50\%, and n(Al+Fe):nSi 10:1. (3) Through experiments, we optimized the modification conditions. The PSAFS was modified when nMn:nSi was 6:1, nMg:nSi was 1:1, nZn:nSi was 4:1, and the demulsification and oil-removal capacity of four coagulants were obtained: n-PSAFS $>$ Zn-PSAFS $>$ Mg-PSAFS $>$ PSAFS. (4) From the IR spectra of the four coagulants, it can be seen that $\mathrm{Al}, \mathrm{Fe}, \mathrm{Mn}, \mathrm{Mg}, \mathrm{Zn}$, and their hydrolyzed complex ions react with polysilicic acid to form a macromolecule. The absorption peaks generated near $604 \mathrm{~cm}^{-1}$ to $1200 \mathrm{~cm}^{-1}$, which is the main difference between the modified coagulants and PSAFS, and it is the key to reflect the effect of the modified coagulants on emulsified oil wastewater treatment. (5) SEM was used to observe the internal structure of Mn-PSAFS, Zn-PSAFS, Mg-PSAFS, and PSAFS. Both Mn-PSAFS and PSAFS were spatial network structures. However, the structure of Mn-PSAFS was most special, fibrous, and its arrangement was more compact than PSAFS. Both Zn-PSAFS and Mg-PSAFS had a layered structure, and the flaky particles were regularly packed together and had a larger surface area than PSAFS. Zn-PSAFS not only had a chain network structure but also had spherical particles formed on flaky particles, which was a distinguishing feature from other coagulants. After comparing the spatial structure and experimental data, we believe that the fibrous granules of Mn-PSAFS were more conducive to the attachment and aggregation of oil particles, so it had better demulsification and oil-removal capacity.

Author Contributions: Z.Y. contributed to the experimental design and sourcing of the laboratory equipment and raw materials; L.Z. contributed to the experimental operation, data collection, and writing of the manuscript; Y.S. carried out the SEM and IR spectroscopy analysis and the correction and editing of the manuscript; S.Z. and K.J.S. also contributed in the experimental design and correction of the manuscript. 
Funding: This research was funded by the National Natural Science Foundation of China (No. 51508268), the Natural Science Foundation of the Jiangsu Province in China (No. BK20150951), the National Key Research and Development Program of China (2017YFB0602500), and the China Postdoctoral Science Foundation (No. 2016M591835). K. J. Shah was supported by the Ministry of Science and Technology (MOST) of Taiwan (R.O.C.) under grant number MOST 107-3113-E-007-002.

Acknowledgments: The authors gratefully acknowledge Luguang Zhang, who graduated from the College of Urban Construction of Nanjing Tech University, who has given us many useful ideas and suggestions.

Conflicts of Interest: The authors declare no conflict of interest.

\section{References}

1. Colla, V.; Branca, T.A.; Rosito, F.; Lucca, C.; Vivas, B.P.; Delmiro, V.M. Sustainable reverse osmosis application for wastewater treatment in the steel industry. J. Clean. Prod. 2016, 130, 103-115. [CrossRef]

2. Razali, M.; Kim, J.F.; Attfield, M.; Budd, P.M.; Drioli, E.; Lee, Y.M.; Szekely, G. Sustainable wastewater treatment and recycling in membrane manufacturing. Green Chem. 2015, 17, 5196-5205. [CrossRef]

3. Li, W.-W.; Yu, H.-Q.; He, Z. Towards sustainable wastewater treatment by using microbial fuel cells-centered technologies. Energy Environ. Sci. 2014, 7, 911-924. [CrossRef]

4. Xue, Z.X.; Cao, Y.Z.; Liu, N.; Feng, L.; Jiang, L. Special wettable materials for oil/water separation. J. Mater. Chem. A 2014, 2, 2445-2460. [CrossRef]

5. Hassler, B. Accidental Versus Operational Oil Spills from Shipping in the Baltic Sea: Risk Governance and Management Strategies. Ambio 2011, 40, 170-178. [CrossRef] [PubMed]

6. Xiong, S.; Long, H.; Tang, G.; Wan, J.; Li, H. The management in response to marine oil spill from ships in China: A systematic review. Mar. Pollut. Bull. 2015, 96, 7-17. [CrossRef] [PubMed]

7. Liubartseva, S.; De, D.M.; Oddo, P.; Coppini, G.; Pinardi, N.; Greggio, N. Oil spill hazard from dispersal of oil along shipping lanes in the Southern Adriatic and Northern Ionian Seas. Mar. Pollut. Bull. 2015, 90, $259-272$. [CrossRef] [PubMed]

8. King, G.M.; Kostka, J.E.; Hazen, T.C.; Sobecky, P.A. Microbial responses to the deepwater horizon oil spill: From coastal wetlands to the deep sea. Ann. Rev. Mar. Sci. 2015, 7, 377. [CrossRef] [PubMed]

9. Choi, S.W.; Zhang, Y.; Xia, Y. Fabrication of microbeads with a controllable hollow interior and porous wall using a capillary fluidic device. Adv. Funct. Mater. 2009, 19, 2943-2949. [CrossRef] [PubMed]

10. Lin, B.; Lin, C.-Y.; Jong, T.-C. Investigation of strategies to improve the recycling effectiveness of waste oil from fishing vessels. Mar. Policy 2007, 31, 415-420. [CrossRef]

11. Tavakoli, M.T.; Amdahl, J.; Leira, B.J. Experimental investigation of oil leakage from damaged ships due to collision and grounding. Ocean Eng. 2011, 38, 1894-1907. [CrossRef]

12. Teduka, M.; Nishioka, T. Ambient-temperature fusible filter: A preliminary experiment and a proposal for a filtration process. AIChE J. 2014, 60, 22-26. [CrossRef]

13. $\mathrm{Gu}, \mathrm{Y}$; Li, D. Electric charge on small silicone oil droplets dispersed in ionic surfactant solutions. Colloids Surf. A Physicochem. Eng. Asp. 1998, 139, 213-225. [CrossRef]

14. Gupta, V.K.; Ali, I.; Saleh, T.A.; Nayak, A.; Agarwal, S. Chemical treatment technologies for waste-water recycling-An overview. RSC Adv. 2012, 2, 6380-6388. [CrossRef]

15. Zhu, L.; Chen, M.; Dong, Y.; Tang, C.Y.; Huang, A.; Li, L. A low-cost mullite-titania composite ceramic hollow fiber microfiltration membrane for highly efficient separation of oil-in-water emulsion. Water Res. 2016, 90, 277-285. [CrossRef] [PubMed]

16. Wu, W.; Huang, R.; Qi, W.; Su, R.; He, Z. Bioinspired peptide-coated superhydrophilic poly (vinylidene fluoride) membrane for oil/water emulsion separation. Langmuir 2018, 34, 6621-6627. [CrossRef] [PubMed]

17. Sun, G.D.; Xu, Y.; Jin, J.H.; Zhong, Z.P.; Liu, Y.; Luo, M.; Liu, Z.P. Pilot scale ex-situ bioremediation of heavily PAHs-contaminated soil by indigenous microorganisms and bioaugmentation by a PAHs-degrading and bioemulsifier-producing strain. J. Hazard. Mater. 2012, 233-234, 72-78. [CrossRef] [PubMed]

18. Dellagnezze, B.M.; Vasconcellos, S.P.; Angelim, A.L.; Melo, V.M.M.; Santisi, S.; Cappello, S.; Oliveira, V.M. Bioaugmentation strategy employing a microbial consortium immobilized in chitosan beads for oil degradation in mesocosm scale. Mar. Pollut. Bull. 2016, 107, 107-117. [CrossRef] [PubMed]

19. Lee, K.E.; Morad, N.; Teng, T.T.; Poh, B.T. Development, characterization and the application of hybrid materials in coagulation/flocculation of wastewater: A review. Chem. Eng. J. 2012, 203, 370-386. [CrossRef] 
20. Elimelech, M.; Gregory, J.; Jia, X. Particle Deposition and Aggregation: Measurement, Modelling and Simulation; Butterworth-Heinemann: Oxford, UK, 2013; ISBN 1483161374.

21. Matilainen, A.; Vepsäläinen, M.; Sillanpää, M. Natural organic matter removal by coagulation during drinking water treatment: A review. Adv. Colloid Interface Sci. 2010, 159, 189-197. [CrossRef] [PubMed]

22. Luo, Y.; Guo, W.; Ngo, H.H.; Nghiem, L.D.; Hai, F.I.; Zhang, J.; Liang, S.; Wang, X.C. A review on the occurrence of micropollutants in the aquatic environment and their fate and removal during wastewater treatment. Sci Total Environ. 2014, 473, 619-641. [CrossRef] [PubMed]

23. Gutiérrez, G.; Lobo, A.; Benito, J.M.; Coca, J.; Pazos, C. Treatment of a waste oil-in-water emulsion from a copper-rolling process by ultrafiltration and vacuum evaporation. J. Hazard. Mater. 2011, 185, 1569-1574. [CrossRef] [PubMed]

24. Daud, Z.; Awang, H.; Nasir, N.; Ridzuan, M.B.; Ahmad, Z. Suspended solid, color, COD and oil and grease removal from biodiesel wastewater by coagulation and flocculation processes. Procedia Soc. Behav. Sci. 2015, 195, 2407-2411. [CrossRef]

25. Zhao, J.-R.; Xie, H.; Shi, C.-M.; Chen, Z. Study on Treatment of Landfill Leachate by Combined Coagulation-Electrolytic Method. Environ. Sci. Technol. 2010, 33, 188-191.

26. Wei, Y.; Ding, A.; Dong, L.; Tang, Y.; Yu, F.; Dong, X. Characterisation and coagulation performance of an inorganic coagulant-poly-magnesium-silicate-chloride in treatment of simulated dyeing wastewater. Colloids Surf. A Physicochem. Eng. Asp. 2015, 470, 137-141. [CrossRef]

27. Yi, Q.; Long, L. Synthesis of PSAFS using Bayer red mud and its flocculation effect evaluation. Environ. Sci. Technol. 2012, 35, 134-138.

(c) 2018 by the authors. Licensee MDPI, Basel, Switzerland. This article is an open access article distributed under the terms and conditions of the Creative Commons Attribution (CC BY) license (http:/ / creativecommons.org/licenses/by/4.0/). 